\title{
Experiences with BC First Nations community-based radon testing: Successes and lessons learned
}

\author{
Casey Neathway*, Anne-Marie Nicol ${ }^{\dagger}$, Lydia $\mathrm{Ma}^{\dagger}$ \\ *First Nations Health Authority \\ ${ }^{\dagger} \mathrm{NCCEH}$
}

\section{Introduction}

Radon is a colourless, odourless gas that is released from the degradation of uranium naturally present in rock and soil. Radon poses a health risk when it enters buildings and homes through cracks and openings in their foundations, with levels differentially higher in lower floors (e.g., basements) as compared with higher floors (National Collaborating Centre for Environmental Health, 2017). While radon concentrations vary regionally, levels are dependent on the geography of uranium deposits. In Canada, radon is the second leading cause of lung cancer for smokers (Health Canada, 2016), and the second leading cause of lung cancer in the country (Taylor, 2017). Health Canada recommends mitigation methods to reduce radon levels in homes and buildings that test above 200 Becquerels per metre cubed $\left(\mathrm{Bq} / \mathrm{m}^{3}\right)$ (Health Canada, 2014). There is limited information available on the impact of radon on the health of on-reserve First Nations populations, ${ }^{1}$ though some radon-related risk factors are known to be higher in First Nations communities: housing conditions are generally poorer on-reserve, with $28 \%$ of houses needing major repairs compared with $7 \%$ for the national average (Statistics Canada, 2017c). In addition to the carcinogenic effects of radon, housing is also a determinant of health, with both mental and physical diseases being associated with poor housing (National Collaborating Centre for Aboriginal Health, 2017). Smoking has been shown to increase lung cancer rates by up to 25 times in the presence of radon (Darby et al., 2005), and $39 \%$ of the First Nations population over 12 years of age smokes recreational tobacco, compared with $15 \%$ of the non-Indigenous population (Statistics Canada, 2015b). With over 3000 lung cancer deaths attributable to radon in Canada annually (McQuillan, 2017), and with "the future cancer burden expected to be high in the First Nations on-reserve population" (Elias et al., 2011), it is important to identify and to mitigate radonrelated cancer risks in on-reserve housing across Canada.

To assess the radon-related risk for on-reserve residents, it was necessary to test homes for indoor radon levels. Previous radon sampling on reserve had occurred, but no comprehensive residential radon sampling program has thus far been conducted in British Columbia (BC). The majority of radon sampling previously completed in First Nations communities occurred in public buildings and not in private homes. As residential radon levels can vary significantly between individual homes (Sarkar et al., 2017), the First

Corresponding author: Casey Neathway (Casey.Neathway@fnha.ca)

Nations Health Authority (FNHA) sought to test as many individual on-reserve homes as possible. Encouraging testing is known to be challenging and the federal government found that fewer than $6 \%$ of Canadians who have heard of radon have tested their homes (Statistics Canada, 2016). For radon testing on reserves, specific considerations were expected, including gaining access to private residences for detector deployment and obtaining the support of leadership in communities who have limited time and may have limited financial resources.

This paper will describe the key components of a three-year, on-reserve, community-wide residential radon testing project involving three Interior BC First Nations communities that resulted in an impressive $97 \%$ response rate for radon testing. The paper highlights the activities and considerations that led to the success of this program and offers insights into how testing rates can be increased for environmental health service organizations and other groups working with communities who face challenges similar to those identified in the participating First Nations communities (Nicol et al., 2015).

\section{Background}

The First Nations Health Authority (FNHA) was established on October 1, 2013, with an historic transfer of programs, services, staff, and responsibilities from Health Canada's First Nations Inuit Health Branch (FNIHB). The tripartite agreement between the First Nations Health Council, the Province of British Columbia, and the Government of Canada created a first of its kind, Indigenous-led, health service delivery organization. Under the vision statement of "healthy, self-determining and vibrant BC First Nations children, families, and communities," FNHA works collaboratively with federal and provincial partners to collaborate, coordinate, and integrate health programs and services (First Nations Health Authority, 2013c).

Transferred services from FNIHB to FNHA included Environmental Public Health programming, with FNHA employing Environmental Health Officers (EHOs), some of whom were previously employed by Health Canada. EHOs are assigned to one or more communities and work with First Nations to develop annual work plans, with a "communitydriven, nation-based" approach to identifying specific priorities (First Nations Health Authority, 2013a). When providing services to First Nations communities, FNHA refers to the First Nations Perspective on Health and Wellness to guide policy 
decisions (First Nations Health Authority, 2013b). This perspective considers the role of social, cultural, economic, and environmental determinants of health, as well as the role that the land plays into individual well-being. These considerations of varied influences on human health allow for a broad perspective on interventions that can lead to positive outcomes.

In 2016, 270,585 people identified as Indigenous in BC, comprising nearly $6 \%$ of the province's population (Statistics Canada, 2017a). Of these individuals, 172,520 (63.8\%) identified as First Nations with $40.1 \%$ of these individuals living onreserve (Statistics Canada, 2017b).

\section{Radon testing program: methods}

The radon program was conducted in two phases. Phase One ran from November 2015 to February 2016 and Phase Two from April 2016 to March 2017. Both phases used the same radon test kits, Radonova's Radtrak Alpha Track Detector. These small, nontoxic, passive detectors are left for at least 91 days in the home to test for the level of radon gas.

Health Canada recommends radon detectors be placed in the "normal occupancy area of the lowest lived-in level of the home" (Health Canada, 2017), where occupancy is defined as being occupied for more than four hours per day. This study sought to identify the maximum hazard potential and thus detectors were generally deployed to the lowest "livable" space in the home. As overcrowding is an identified and prevalent concern in onreserve homes (Statistics Canada, 2015a), the consideration was made that any "livable" space could become an occupancy area.

In both phases, when testing was completed, detectors were collected by FNHA or community staff. This flexible collection process was made possible by thorough record keeping and communication between all program participants. At the time of collection, there were further opportunities for information exchange to residents to ensure they were fully aware of timelines and next steps.

\section{Phase One radon testing program}

FNHA obtained radon detectors through a partnership with BC's Interior Health Authority (IHA), who received funding provided by a grant from Health Canada that was used in part to purchase the detectors.

From November 2015 to February 2016, the Radon Potential Map of BC (Figure 1) (Radon Environmental Management Corporation, 2015) was used to identify communities in higher radon potential regions. These communities were approached by FNHA Environmental Health (EH) staff to gauge community interest and capacity to participate in radon testing. Six First Nations in this region of the health authority agreed to participate in a sampling program and a total of 100 test kits were distributed. Two of these communities offered to share their experiences from their testing programs, with results as described in Table 1.

\section{Identifying community champions}

Previous research has outlined the value of participatory research in First Nations communities, contributing to more trust and credibility, and "providing access to critical information" (Kwiatkowski, 2011). This is also a fundamental component of the work of FNHA, ensuring the "community driven, nation based" approach (First Nations Health Authority, 2013a). Community champions, including elected Chiefs, housing managers, and community health representatives from participating First Nations communities provided radon information

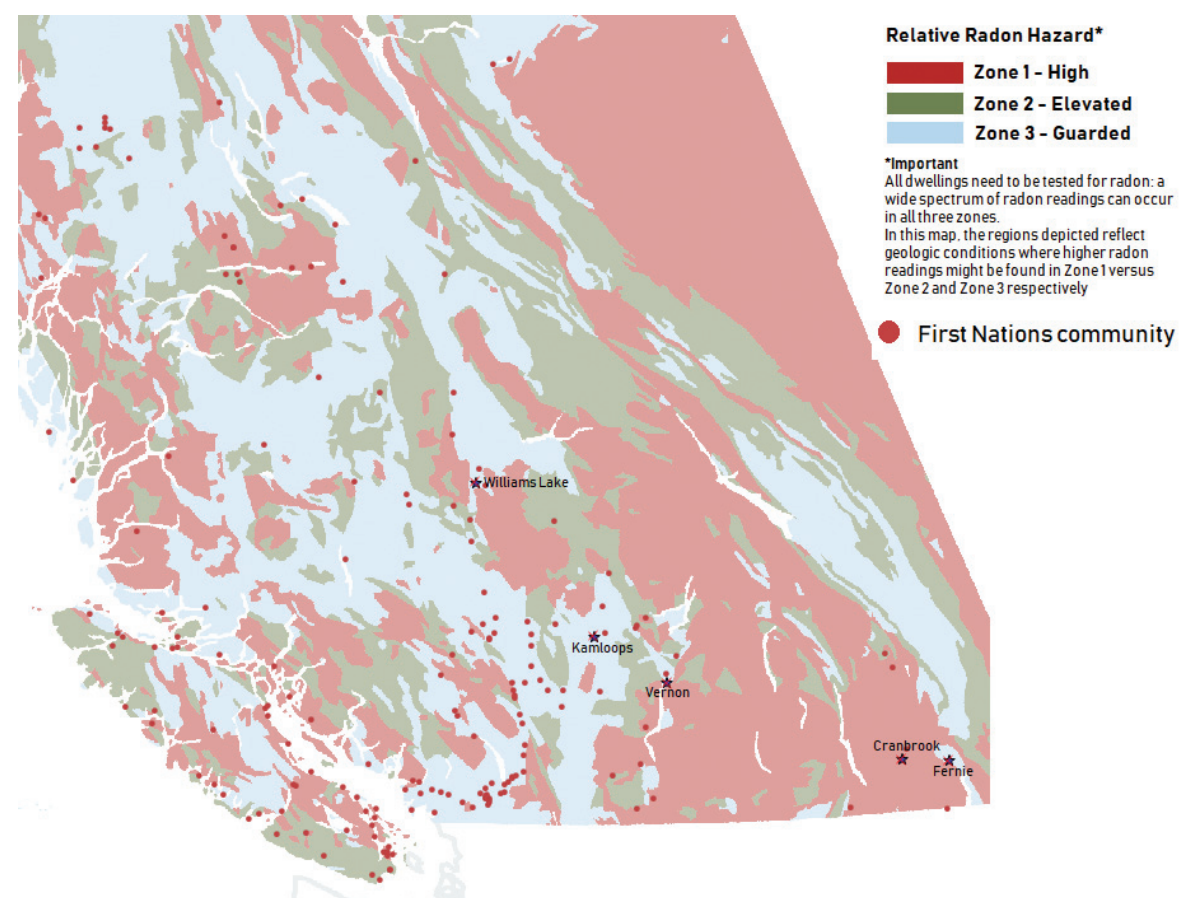

Figure 1. Radon potential map showing locations of southern BC First Nations communities as compared to relative radon hazard. Radon potential map used with permission from Radon Environmental Management Corp. 
to their community members, supported deployment activities, were key points of contact with FNHA staff, and were responsible for sharing testing results with residents. The specific community roles and positions of these champions were important, as individuals such as housing managers have the ability to positively influence decision-making in community members and First Nation leadership.

\section{Community education and outreach}

Availability of education resources and outreach activities were important for the success of the program. The FNHA/ IHA partnership co-developed how-to guides for test deployment and information handouts about the health effects of radon for both First Nation staff and residents. These resources were distributed at the time of deployment, and participants were given an opportunity to ask questions. The deployment of radon detectors was performed by both FNHA and community staff, depending on the First Nation's capacity and location.

Upon completion of the testing period, FNHA received and shared radon test results with community champions for detectors that originated with the Health Authority. FNHA also shared, either directly or through community champions, individual test results with residents and included an accompanying letter outlining the risk of radon at specific levels, recommended actions, and next steps. This correspondence included an offer for telephone follow-ups if specific questions arose.

The success and lessons learned from Phase One were shared by community champions and EHOs. This was effective in recruiting more community champions and raised awareness of the radon testing program in additional communities. It is important to note that community champions involved in Phase
One continued to engage with their own communities on radon education as well as with advocating and facilitating continuing testing in additional homes, often with minimal support necessary from FNHA.

\section{Phase Two radon testing program}

From April 2016 to March 2017 continued sampling was done in the two Phase One communities that expressed interest in further testing. Additional First Nations communities throughout BC were recruited, including four from the Interior Region.

\section{Results}

Overall, 400 test kits were deployed through this program: 230 in FNHA's Interior Region and 170 in the Northern and Fraser regions, with distribution shown in Figure 2. The response rate for the Interior communities was $92 \%$; data are not yet available to determine the response rate from the Northern and Fraser communities. Three communities with champions in the Interior Region agreed to share their experiences with radon test results provided in Table 1.

In these three communities, the majority of homes reported results below Health Canada's recommended level of $200 \mathrm{~Bq} / \mathrm{m}^{3}$. Phase One had a higher proportion of homes with elevated radon, which may be due to how the homes were selected (using regions labelled "high" on the radon potential map), although it is recognized that the sample size is small $(n=20)$. Within the two Phases, one home tested above $600 \mathrm{~Bq} / \mathrm{m}^{3}$, the level at which Health Canada recommends mitigation within one year.

Table 1. Radon testing results from three specified Interior Region communities

\begin{tabular}{|l|c|c|c|c|c|}
\hline & No. of kits deployed & No. of kits collected & Below $\mathbf{2 0 0} \mathbf{~ B q} / \mathbf{m}^{3}$ & $\mathbf{2 0 0}-\mathbf{6 0 0} \mathbf{~ B q} / \mathbf{m}^{3}$ & $\mathbf{A b o v e ~ 6 0 0 ~ B q} / \mathbf{m}^{3}$ \\
\hline Phase One & 20 & $19(95 \%)$ & $14(74 \%)$ & $5(26 \%)$ & 0 \\
\hline Phase Two & 75 & $72(96 \%)$ & $63(88 \%)$ & $8(11 \%)$ & $1(1 \%)$ \\
\hline
\end{tabular}

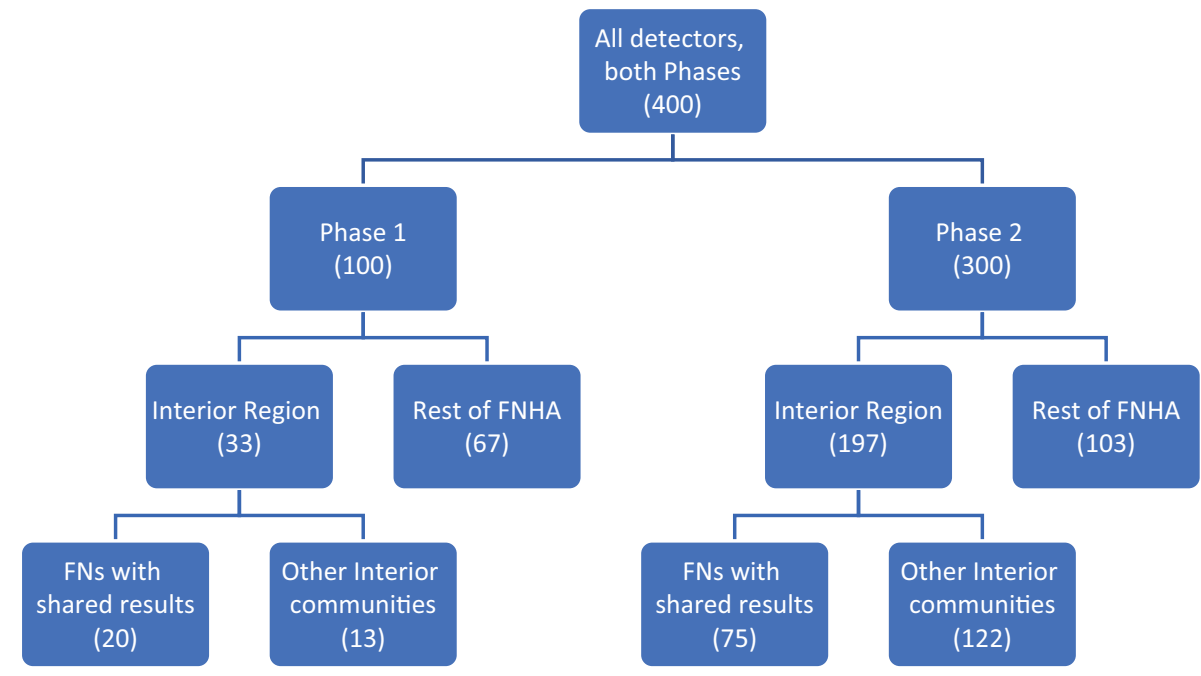

Figure 2. Distribution of radon detectors. Number in brackets is number of detectors deployed in each stage. 


\section{Discussion}

Although awareness of radon is growing in Canada, the rate of people testing their homes remains very low. Various strategies have been tried to increase treating across a range of housing and community types. To date, little work has been reported from on-reserve First Nations communities. The program described in this paper met with significant success in engaging First Nations communities on the topic of radon, encouraging testing homes and, importantly, having their participation in testing their homes for radon levels.

Regarding the results from the three communities, previous studies have shown that between $6 \%$ and $30 \%$ of homes in the Northern and Interior regions of BC had radon levels above $200 \mathrm{~Bq} / \mathrm{m}^{3}$ (Healthlink, 2016). The Cross-Canada Survey of Radon Concentrations in Homes (Health Canada, 2012) identified $7.9 \%$ of $\mathrm{BC}$ homes having radon concentrations above $200 \mathrm{~Bq} / \mathrm{m}^{3}$, with $1.2 \%$ of these testing above $600 \mathrm{~Bq} / \mathrm{m}^{3}$. Although the results in this study fell between these findings, given the selection of First Nations in higher radon potential areas, a larger percentage of exceedances was expected. Sarkar (2017) noted that "there is a possibility of the existence of a highrisk community in a low-risk region". The inverse can also be true, with lower-risk homes existing in high radon potential areas.

Due to relatively small sample sizes, it is difficult to generalize radon levels in First Nations housing from this work. Additionally, this study did not include information on housing characteristics that could have higher association with risk from radon ingress. More results, coupled with data on housing age, design, and use patterns, would be needed to better characterize radon levels and risk in First Nations housing in these regions (Stanley et al., 2017).

While radon testing was the aim of this project, the establishment of this type of radon testing program and the lessons learned in working with communities were also objectives. This work identified several key elements that associated with successes and barriers in community-wide radon projects.

\section{Challenges to community-wide radon testing}

\section{Financial barriers}

Access to funding for mitigation work on nonband-owned homes can be an impediment to reducing radon-related risks. Housing budgets for First Nation communities are limited (Assembly of First Nations, 2013), there are competing priorities for maintenance dollars, and individual residents may not be able to afford mitigation. Some First Nation communities and their members were not willing to have their homes tested if they were not able to access funds for mitigation. Although some mitigation funds may be available from Indigenous Services Canada (ISC), this will not necessarily be applicable to privately owned homes, and the application process requires additional human resource capacity within the First Nation.

\section{Lack of trained radon mitigators}

FNHA strongly recommended the use of Canadian - National Radon Proficiency Program (C-NRPP) certified mitigators. However, access to C-NRPP mitigators can be challenging in more remote communities, and the cost of travel can add significantly to the already challenging mitigation costs.

\section{Individual considerations}

FNHA has found that some First Nation communities, including those in areas with a high radon potential, do not have any interest in a community-wide testing project, even though EHOs have spent significant time educating about the risks of radon. Weinstein (1991) found similar challenges in encouraging home-based radon testing, showing no difference in testing behaviour between individuals who received a mail-out brochure or telephone call and those who did not receive any intervention (Weinstein and Sandman, 1992). FNHA continues to provide outreach and education to these communities and individuals and will work with First Nations to find champions to assist in this outreach.

\section{Program characteristics leading to success Giving support and gaining trust}

First Nation communities often experience staff capacity challenges in their housing programs (British Columbia Assembly of First Nations, 2017). To ensure radon testing did not add additional challenges, FNHA made EHOs available to deploy detectors and provide ongoing support. FNHA also employs Environmental Health Technicians (EHTs) who work alongside EHOs in a supporting role, who self-identify as indigenous, and often have strong ties to the communities with which they work. The EHTs received training on detector deployment and supported the EHOs or worked with community champions to assist deployment activities. This extra capacity within FNHA has allowed for a much greater engagement with communities in the actual activities of deployment and collection of detectors.

Building trust was also a key component for the success of this program. First Nation community staff accompanied EHOs during home visits to show community-level buy-in of the testing, so community-specific questions could be answered by those knowledge holders, and so local context could be provided by an appropriate authority.

\section{Capitalizing on administrative opportunities}

On-reserve housing inspections are one of the program areas delivered by FNHA EH professionals, and housing health and safety is within FNHA's mandate. Nicol et al. (2015) identified these on-site inspections as an opportunity to "discuss radon with owners and operators of ground- and basement-level facilities" (Nicol et al., 2015). FNHA EHOs are able to include radon conversations in their discussions of housing health with residents. On-reserve housing inspections, which may not occur for each home, can be used in addition to community meetings, engagement sessions, and deployment activities to provide radon information to residents in a neutral setting. EH programs that do not provide housing inspections may not have this opportunity to engage with residents, and the advice given by Nicol et al. (2015) is more appropriate. Handouts and printed materials available for distribution were developed at an organizational level so EHOs 
were not responsible for creating their own resources. Resources were all developed in English for the greatest reach. Future work could include translating these documents into BC's mostspoken Indigenous languages to help communication, especially for residents who may not speak English.

\section{Identifying and leveraging First Nations Community Champions}

Each First Nation who participated in the successful wide-scale radon testing program had at least one community champion as a key point of contact with FNHA. These community champions coordinated deployment of detectors, meetings with community members, education of the public, and oversaw mitigation activities. In two communities, the champions were responsible for deployment of detectors within their First Nations. Community champions came from varied positions within the First Nation, and included health directors, housing managers, and band administrators. While not engaging in the deployment or technical work, elected band representatives (Chiefs and Councilors) played important supporting roles as advocates, enabling their staff to act as community champions. As not every community will have the same structure, the community champion may not always be in the same role. The EHO's knowledge of and contacts within the First Nation and understanding of the community dynamics were helpful in identifying key players and who to approach as a community champion.

The success of the radon testing program in First Nations on-reserve communities is attributable to the role of the community champions, from liaising with community members to being involved with deployment and retrieval of radon detectors to educating the public. Phase Two saw the introduction of one additional community champion among the four Interior communities who tested, and there was significant deployment and detector return success due to this individual's influential role as a housing manager and their commitment to implementing a testing program. Each community that participated in significant sampling had the support of leadership, and FNHA saw increased interest from communities where the champion was a respected person within the First Nation community and showed enthusiasm for participating in radon activities. Community champions who are seen as trusted subject matter experts (either in housing, health, or administration) are able to engage with residents to increase participation at a level that $\mathrm{EHOs}$ and $\mathrm{EH}$ programs cannot. The use of community champions can serve as a model for other EH community outreach projects in First Nations communities.

\section{Engaging the community and building capacity}

The participation, support, and willingness of First Nation communities were necessary for the success of the community-wide radon testing program. In some of the participating First Nation communities, radon awareness was included as part of presentations at community meetings and testing was offered directly to residents. In other locations, community champions would use their existing relationships with members to inform them about radon and the possibility of testing. In no circumstances were residents forced to accept radon detectors in their homes, and care was taken to spend as much time as needed to answer any questions they had.

Capacity building within First Nations is an important aspect of FNHA's approach to service delivery. Where possible, First Nation staff received guidance on all aspects of the radon program to allow them to be in control of the project. This allows for future and ongoing radon detection work to be completed by the communities where resources and staffing are not a barrier, with FNHA providing detectors and EHO support on request. Some communities have already taken on radon testing programs within their own housing department, with FNHA in a consultative role when technical questions arise.

\section{Financial considerations of remediation}

Radon testing and remediation programs require financial support. Even though test kits are inexpensive, large-scale programs can be expensive. This program used bulk purchasing, reducing costs by ordering many detectors and obtaining discounted prices as a government agency, which reduced costs overall and radon test kits were kept on-hand in FNHA offices so that communities could test right away when there was interest. As there are more than 200 First Nation partners throughout the province, the likelihood of using all purchased detectors was high. Test kits are usable up to 18 months after they are purchased.

Remediation of homes generally costs between $\$ 1000$ and $\$ 3000$. In some cases, FNHA helped First Nation communities access mitigations resources when radon levels were above Health Canada guidelines. Through ISC's Immediate Needs Fund, which provides for "construction, renovation, and lot servicing funding" for communities, First Nations can access funding for mitigating band-owned homes (Indigenous Services Canada, 2016). Typically accessing this fund requires an inspection report, radon test result, or letter of support from an EHO. First Nations housing managers, who are often experienced in applying through this fund for mold remediation and other urgent maintenance, can use the same process to access radon mitigation funding. While ISC is not able to guarantee funding prior to receiving and reviewing the individual application, their staff have been willing to meet with First Nation communities prior to testing to informally assess eligibility. Some First Nations had the capacity to mitigate homes within their existing housing budgets, which provided additional incentives to testing for residents. FNHA was able to provide post-testing support by helping to identifying C-NRPP qualified mitigators near the First Nation community and attending community meetings and engagement events to provide information to residents on radon test results and possible remediation actions. FNHA does not act as a housing funding agency, so they did not provide direct monetary support for any mitigation activities.

\section{Study limitations}

This study reflects the experiences of three of 54 First Nations communities, in one of five BC Regions. It is recognized that the findings may not be applicable to all communities. Further, as the study looked specifically at relatively small, on-reserve First Nations communities, activities related to mitigation funding and community champions will not necessarily apply equally to 
larger communities or off-reserve housing. This study does not include data from any communities who did not wish to participate, from any regions other than the Interior, and from any radon tests where the First Nation community was solely responsible for obtaining and deploying detectors, as FNHA plays only a supportive role in self-driven on-reserve activities.

The communities chosen to participate in Phase One of the radon deployment were selected at random, but selection was based on perceived risk from radon potential maps. Communities who participated in Phase Two were self-selected, based on their knowledge of Phase One activities and conversations with their $\mathrm{EHO}$, and were not chosen based on geographic potential. Two communities had engaged in radon testing beyond previous Health Canada studies and had community champions who were already knowledgeable about radon risks. It is recognized that this existing knowledge and interest likely contributed to the success of a community-wide deployment.

\section{Informing future work}

Subsequent to Phase Two, FNHA has ordered more than 1400 additional detectors for deployment across the province. The Interior FNHA Region has worked with communities to deploy them in more than half of Interior BC First Nation communities. FNHA continues to discuss sampling programs with community leadership, especially in higher radon potential areas, with a goal of $100 \%$ participation of First Nations in the Region. Detectors are being deployed, starting in January 2018, in schools and provincially licensed on-reserve daycares and Aboriginal Head Start On Reserve programs (http:// www.fnha.ca/what-we-do/maternal-child-and-family-health/ aboriginal-head-start-on-reserve) as required by some Regional Health Authorities in the province (Interior Health Authority, 2017). Where FNHA EHOs attend new child care facilities in the process of becoming licensed, they will provide information about radon as part of their inspection process.

To better understand the role that housing construction has on radon levels in First Nation communities, ongoing radon work by FNHA will include a survey of housing conditions and construction, similar to that described by Sarkar, in which data on the type of residence, foundation and floor type, existence of a basement, and number of rooms were collected when detectors were deployed (Sarkar, 2017). This information, along with radon testing results, will be compiled along with other inspection information to provide a more fulsome picture of health impacts related to on-reserve housing.

Due to the substantial negative health impacts of radon exposure to smokers (Darby et al., 2005), FNHA intends to include this information as part of the Respecting Tobacco program (First Nations Health Authority, 2017). Through partnerships with other departments within the organization, the FNHA $\mathrm{EH}$ program will be able reach broader audiences to educate about the risks of smoking and radon exposure and offer testing services. Brochures and information handouts are being developed by FNHA to support this knowledge transfer.

FNHA is interested in supporting community members to become C-NRPP certified mitigators as a means of increasing community capacity, in accordance with the organization's Directive \#5 (First Nations Health Authority, 2013a). As both the cost of mitigation and access to C-NRPP certified contractors have been identified as challenges for First Nations, this could reduce mitigation costs and allow for collaborative partnerships between communities toward reducing radon exposure.

\section{Conclusion}

First Nations community members living in high radon geographic areas are potentially exposed to a known human carcinogen (International Agency for Research on Cancer, 1988). Tobacco smoking has been shown to have multiplicative effects on health (Darby et al., 2005). A public health intervention begins with knowing the extent of the problem via testing and the target group who is potentially affected, then removing the environmental hazards to prevent harm. By providing resources to communities, large-scale radon testing projects can be successful to identify the extent of the risk. EH program support, including bulk purchasing of detectors, education materials, and human resources for deployment and collection can reduce barriers for communities. This study demonstrates that return rates of detectors is increased through collection of detectors by community champions

This study shows that having community champions is key to a successful community-wide testing program. Their knowledge and presence within the community provides supports that an EH program cannot. Their advocacy and information sharing with community members is often better received than that provided by an EHO. Ongoing engagement with the community throughout the sampling program is essential, both to increase knowledge of radon amongst residents and to ensure champions feel supported by the Health Authority.

Access to affordable mitigation strategies is a barrier to reducing radon exposures and sampling in some First Nation communities. ISC or First Nation-funded mitigation and C-NRPP certified community members can help to reduce these challenges.

Ongoing work is necessary to fully identify the scope of radon-related health impacts on First Nation communities in $\mathrm{BC}$, as well as the role of on-reserve housing construction practices in determining indoor radon concentrations. Factors for success and potential barriers identified in this work with BC First Nation communities can encourage others across Canada to undertake public health measures that include radon testing for existing properties, mitigation assistance, and adopting radon-resistant new construction of homes and facilities.

\section{Acknowledgements}

This work has been completed under a secondment with the National Collaborating Centre for Environmental Health $(\mathrm{NCCEH})$ and production of this document has been made possible through a financial contribution from the Public Health Agency of Canada through the National Collaborating Centre for Environmental Health. The authors thank Michele Wiens, Information Specialist of NCCEH for her input and edits, and the National Collaborating Centre for Aboriginal Health 
for reviewing this paper. This work would not be possible without the contributions of First Nations communities and staff throughout the Ktunaxa and Secwepemc Nations. Significant thanks are due to Greg Baytalan, Specialist Environmental Health Officer of Interior Health Authority, whose support and outreach led to the partnership described in Phase One.

\section{Note}

1. Indigenous peoples are the original inhabitants of Canada and their descendants, including First Nations (referred to as Indians in Canadian Constitution), Inuit, and Métis peoples as defined by Section 35 of the Canadian Constitution of 1982.

\section{References}

Assembly of First Nations. 2013. Fact sheet - First Nations housing on-reserve. Ottawa, ON: Assembly of First Nations.

British Columbia Assembly of First Nations. 2017. Creating a First Nations housing and infrastructure authority: From concept to design. Kamloops, BC: British Columbia Assembly of First Nations.

Darby, S., Hill, D., Auvinen, A., Barros-Dios, J. M., Baysson, H., Bochicchio, F., Deo, H., Falk, R., Forastiere, F., Hakama, M., et al. 2005. Radon in homes and risk of lung cancer: Collaborative analysis of individual data from 13 European case-control studies. Br Med J. 330(7485): 223. doi: 10.1136/bmj.38308.477650.63

Elias, B., Kliewer, E. V., Hall, M., Demers, A. A., Turner, D., Martens, P., Hong, S. P., Hart, L., Chartrand, C., \& Munro, G. 2011. The burden of cancer risk in Canada's indigenous population: A comparative study of known risks in a Canadian region. Int J Gen Med. 4: 699-709. doi: 10.2147/IJGM.S24292

First Nations Health Authority. 2013a. Directives. West Vancouver, BC: First Nations Health Authority.

First Nations Health Authority. 2013b. First Nations perspective on wellness. West Vancouver, BC: First Nations Health Authority.

First Nations Health Authority. 2013c. Vision, mission and values. West Vancouver, BC: First Nations Health Authority.

First Nations Health Authority. 2017. Respecting tobacco. West Vancouver, BC: First Nations Health Authority.

Health Canada. 2012. Cross-Canada survey of radon concentrations in homes. Final report. Ottawa, ON: Health Canada.

Health Canada. 2014. Radon - Reduction guide for Canadians. Ottawa, ON: Health Canada.

Health Canada. 2016. Radon - Another reason to quit. Ottawa, ON: Health Canada.

Health Canada. 2017. Guide for radon measurements in residential dwellings (homes. ). Ottawa, ON: Health Canada.

Healthlink, B. C. 2016. Radon in homes and other dwellings. Victoria, BC: Healthlink BC.
Indigenous Services Canada. 2016. On-reserve housing immediate needs fund guidelines. Ottawa, ON: Indigenous Services Canada.

Interior Health Authority. 2017. News and resources from licensing May 2017. Kelowna, BC: Interior Health.

International Agency for Research on Cancer. 1988. Man-made mineral fibres and radon. Lyon, France: World Health Organization.

Kwiatkowski, R. E. 2011. Indigenous community based participatory research and health impact assessment: A Canadian example. Environ Impact Assess Rev. 31(4): 445-450. doi: 10.1016/j.eiar.2010.02.003

McQuillan, L. 2017. Radon: A silent threat. Ottawa, ON: Canadian Public Health Association.

National Collaborating Centre for Aboriginal Health. 2017. Housing as a social determinant for First Nations, Inuit, and Métis health. Prince George, BC: National Collaborating Centre for Aboriginal Health.

National Collaborating Centre for Environmental Health. 2017. Radon in the home. Vancouver, BC: NCCEH.

Nicol, A.-M., Rideout, K., Barn, P., Ma, L., \& Kosatsky, T. 2015. Radon: Public health professionals can make a difference. Environ Health Rev. 2015. 58(1): 7-8. doi: 10.5864/d2015-003

Radon Environmental Management Corporation. 2015. Radon in BC. Vancouver, BC: Radon Environmental Management Corporation.

Sarkar, A., Wilton, D. H., \& Fitzgerald, E. 2017. Indoor radon in micro- geological setting of an indigenous community in Canada: A pilot study for hazard identification. Int J Occup Environ Med. 8(2): 69-79. doi: 10.15171/ijoem.2017.1001

Stanley, F. K., Zarezadeh, S., Dumais, C. D., Dumais, K., MacQueen, R., Clement, F., \& Goodarzi, A. A. 2017. Comprehensive survey of household radon gas levels and risk factors in southern Alberta. CMAJ Open. 5(1): E255-E264. doi: 10.9778/cmajo.20160142

Statistics Canada. 2015a. Housing conditions. Ottawa, ON: Statistics Canada.

Statistics Canada. 2015b. Select health indicators of First Nations people living off reserve, Métis and Inuit. Ottawa, ON: Statistics Canada.

Statistics Canada. 2016. Radon awareness in Canada. Ottawa, ON: Environment, Energy and Transportation Statistics Division.

Statistics Canada. 2017a. Aboriginal Peoples highlight tables, 2016 census. Ottawa, ON: Statistics Canada.

Statistics Canada. 2017b. Focus on geography series, 2016 census. Ottawa, ON: Statistics Canada.

Statistics Canada. 2017c. Housing conditions: Aboriginal people more likely to live in houses requiring major repairs. Ottawa, ON: Statistics Canada.

Taylor, G. P. 2017. Message from the Minister of Health radon action month and lung cancer awareness month - November 2017. Available at: https://www.canada.ca/en/health-canada/news/2017/11/message_ from_theministerofhealthradonactionmonthandlungcancerawa.html [accessed 25 February 2018].

Weinstein, N. D., \& Sandman, P. M. 1992. A model of the precaution adoption process: Evidence from home radon testing. Health Psychol. 11(3): 170-180. doi: 10.1037/0278-6133.11.3.170 